\title{
Política Monetária e Ciclos Regionais no Brasil: Uma Investigação das Condições para uma Área Monetária Ótima
}

\author{
- Vladimir KüHL Teles*
}

- Mauro costa Miranda **

\begin{abstract}
RESUMO
O objetivo deste artigo é realizar a investigação empírica da influência diferenciada da política monetária e dos demais choques de curto prazo sobre o produto agregado de cada uma das regiões brasileiras. $A$ metodologia consistiu em uma combinação de técnicas de componentes não-observados e vetores autoregressivos (VAR). Foram identificadas fontes de inovação comuns e idiossincráticas às regiões bem como respostas comuns e idiossincráticas a tais choques. Os resultados indicam que as regiões brasileiras apresentam efeitos assimétricos a choques comuns de política monetária.
\end{abstract}

\section{Palavras-CHAVE}

vetor auto-regressivo, componentes não-observados, área monetária ótima

\section{ABSTRACT}

The objective of this paper is to investigate the influence of the monetary policy and other shocks on the gross domestic product of each one of the Brazilian regions. The methodology is a combination of nonobserved components and auto-regressive techniques (VAR). Common and specific shocks and common and specific effects of these shocks had been identified. The results indicate that Brazilian regions have symmetric responses to the common shocks but the most important shocks are the idiosyncratic ones.

\section{KEY WORDS}

vector autoregression, unobsorved components, optimal currency area

\author{
JEL CLASSIFICATION \\ E32, E52, RII
}

\footnotetext{
+ Os autores agradecem os comentários valiosos realizados por Adriana Amado, Cláudio Barra Castro e Joaquim P. Andrade e de dois pareceristas anônimos da revista. Agradecem, igualmente, ao Prof. Milton Barossi-Filho pelo fornecimento dos dados do PIB regional. Todos os erros remanescentes são, entretanto, de nossa inteira responsabilidade.

* Fundação Getúlio Vargas, Escola de Economia de São Paulo (EESP/FGV), Rua Itapeva 474, I20. andar, 01332-000, Tel: (II)328I-3378, Fax:(II)328I-3357. E-mail: vkteles@fgvsp.br.

* Universidade de Brasília (UnB). E-mail: curupira@unb.br.
}

(Recebido em agosto de 2003. Aceito para publicação em julho de 2005). 


\section{INTRODUÇÃO}

Uma considerável disputa teórica eleva-se acerca da modelagem teórica de rigidez de preços e/ou salários. No tocante a este aspecto, não há sombra de dúvida de que a forma como a viscosidade dos preços for modelada implica, freqüentemente, diretrizes de política distintas (ver Sims, 1998). Neste sentido, o questionamento que surge a partir desta disputa teórica é: considerando-se que haja possibilidade de a economia ser mais complexa, de modo a haver diversas regras de ajuste de contratos de preços e salários de forma contemporânea na economia, que diretriz de política deve ser adotada?

Tal questão é considerada de forma apropriada por Blinder e Mankiw (1984), que assumem que cada setor industrial escolhe uma regra distinta de ajuste de contratos de preços e salários, em que alguns setores apresentam, por exemplo, regras de ajuste nominal, enquanto outros, regras de ajuste real. Neste sentido, tais autores demonstram que a única possibilidade de uma política monetária afetar a todos os setores igualmente é se eles estiverem sujeitos a choques perfeitamente simétricos, ou seja, na presença de choques assimétricos haveria uma política monetária ótima para cada setor individualmente, de forma que os benefícios ou prejuízos referentes a uma política monetária seriam de magnitudes distintas para cada setor.

Naturalmente, tal discussão estende-se diretamente ao âmbito regional, uma vez que cada região tende a apresentar uma concentração setorial distinta. Os efeitos diferenciados da política monetária protagonizaram as discussóes econômicas relativas à unificação européia. Diversos países demonstraram receio em adotar uma moeda comum, particularmente quanto à possibilidade de que seus interesses fossem preteridos por ocasião da escolha da regra de política monetária a ser adotada. O artigo de Mundell (1961) foi, talvez, o primeiro a abordar a questão da assimetria de efeitos de política monetária. Kouparitsas (1991) propõe uma definição de área monetária ótima: aquela na qual um choque monetário tem efeito relativamente simétrico entre suas regiões componentes. $\mathrm{O}$ autor apresenta quatro critérios necessários e suficientes para que isso aconteça: (i) as regiões estão expostas a fontes similares de distúrbios econômicos (choques comuns); (ii) a importância relativa de tais choques é similar entre as regiões (choques simétricos); (iii) as regióes apresentam respostas similares aos choques comuns (respostas comuns); (iv) se regiões estão sujeitas a um choque específico à sua região (choque idiossincrático), ela se ajusta rapidamente.

O presente artigo se propõe a realizar a verificação empírica da influência diferenciada da política monetária sobre o produto agregado de cada uma das regióes brasileiras. A metodologia a ser utilizada consiste na estimação de um modelo empírico que usa conjuntamente técnicas de componentes não-observados e de vetor auto-regressivo estrutural (VAR), procurando verificar se as regiões brasileiras satisfazem as condi- 
ções de área monetária ótima de Kouparitsas (1991) no período 1947-2000. Tanto os choques monetários quanto as variaçôes do produto agregado de cada região são discriminados em comuns ou idiossincráticos.

A metodologia segue uma variação de um modelo DYMIMIC (general dynamic multiple indicator-multiple cause), que pode ser estimado usando o algoritmo recursivo EM de Watson e Engle (1983). Tal metodologia consiste na estimação de um modelo estado-espaço para a construção de séries não-observadas que, no caso, se referem aos choques regionais comuns e idiossincráticos.

A seção a seguir é destinada à revisão da literatura referente a outros países ou conjuntos de países. A seção 2 apresenta os dados utilizados, em que evidências sobre as propriedades dos ciclos regionais do produto são sugeridas ainda em um caráter preliminar. As seções 3 e 4 descrevem a metodologia e os resultados obtidos. Considerações finais são apresentadas na última seção.

\section{UMA REVISÃO DA LITERATURA}

A diferenciação da atuação de fatores monetários e financeiros sobre regiões econômicas distintas é alvo de literatura em rápida expansão. Dow e Rodriguez-Fuentes (1997) oferecem um panorama recente e abrangente da literatura produzida. Mencionaremos aqui apenas alguns artigos com o propósito de ilustrar as diferentes abordagens adotadas na ciência econômica, a exemplo de Castro (2002). É possível separar dois grupos distintos de estudos. No primeiro caberiam estudos que ressaltam as condições monetárias e financeiras diferentes em regiões distintas de um mesmo país. No segundo, aqueles cujo principal interesse são os efeitos que as condições monetárias e financeiras (regionalmente diferenciadas ou não) teriam sobre as economias de regióes distintas do país.

\subsection{Diferença Regional de Condições Monetárias e Financeiras}

No primeiro grupo considera-se a possibilidade de que a oferta de moeda e crédito seja desigual entre regióes componentes de uma mesma economia nacional. Isto decorreria da estrutura do sistema financeiro e/ou de transações comerciais e financeiras entre regiôes.

Taxas de juros podem variar entre regiões distintas. Fatores que poderiam ser causadores disto são: o número de instituições financeiras e seu grau de concentração em cada região, dificuldade de acesso dos agentes financeiros a informaçôes sobre seus 
clientes quando a região-sede desses clientes encontra-se distante do centro financeiro nacional, e diferentes graus de risco do investimento associados à demanda pelos produtos de uma dada região.

Na Itália, d'Amico, Parigi e Trifildis (1990) e Faini, Galli e Giannini (1993) chegam à mesma conclusão. As taxas de juros praticadas nas regiões nordeste e sudeste da Itália são estatisticamente diferentes, e esta diferença é quase totalmente explicada por diferenças na renda per capita e na distribuição dos devedores por tamanho e setor econômico. Hutchinson e McKillop (1990), por outro lado, verificam que as taxas de juros praticadas em cada país do Reino Unido não são significativamente diferentes entre si.

Alguns autores modelaram diferenças regionais na disponibilidade de crédito. Roberts e Fishkind (1979) indicaram fatores que, distintos em cada região, poderiam implicar tais diferenças: custo de informação sobre condições financeiras, carteira de investimentos do setor não-financeiro, grau de aversão ao risco, tanto por parte de ofertantes quanto de demandantes de crédito, e elasticidades das curvas IS e LM. Moore e Hill (1982) acrescentaram a esses fatores a possibilidade de pequenos ofertantes e demandantes de crédito de regiôes periféricas não terem acesso ao mercado financeiro da região central.

No âmbito da economia pós-keynesiana, a determinação do equilíbrio no mercado de crédito em uma região dependeria das preferências pela liquidez demonstrada por ofertantes e por demandantes de crédito e do estágio de desenvolvimento bancário em cada região.

Nesse sentido, Dow (1982) elaborou modelo no qual o multiplicador monetário varia entre duas regiões (central e periférica). A região central, caracterizada por maior renda e sistema financeiro mais desenvolvido, apresentaria menor preferência pela liquidez e, por conseqüência, maior multiplicador monetário relativamente à região periférica. A possibilidade de transações de moeda e ativos financeiros entre as regiões implicaria que as condiçôes monetárias e financeiras em cada região são mutuamente dependentes. Moore, Karaska e Hill (1985) ampliam essa abordagem para várias regiões e modelam o efeito de multiplicadores diferenciados sobre a renda de cada região.

Dow (1987) agregou novos elementos ao modelo anterior (de 1982), apresentando formas pelas quais ganhos de escala assimilados pelo sistema financeiro nas regiões mais desenvolvidas podem conduzir à concentração dos centros de decisão do sistema financeiro nas regiões centrais e implicar a reprodução e intensificação de desigualdades regionais. Os bancos nacionais, de menor preferência pela liquidez, emprestam menos para a região periférica do que para a central, enquanto bancos da região peri- 
férica, de maior preferência pela liquidez, atuam de forma contrária. Entretanto, como tanto as reservas quanto o multiplicador monetário são maiores nos bancos nacionais do que nos periféricos, a taxa de juros e a oferta de crédito tendem a ser maiores na região central e, por conseqüência, a economia da região central tem maiores incentivos para crescer, acentuando sua diferença em relação à região periférica. Este modelo foi corroborado por evidências estatísticas para os casos do Canadá (Dow, 1990), Escócia (Dow, 1992) e Comunidade Européia (Chick, 1993).

No caso do Brasil, Amado (1997) estudou o desenvolvimento regional brasileiro e os efeitos da moeda e do setor financeiro a partir de uma perspectiva pós-keynesiana, e concluiu que as diferenças econômicas regionais no Brasil são explicadas por relações de dependência centro-periferia que, estabelecidas nos primórdios da história brasilei$\mathrm{ra}$, se reproduziram nas etapas posteriores de desenvolvimento. $\mathrm{O}$ elemento financeiro começaria a desempenhar um papel preponderante nas desigualdades regionais por ocasião da endogeneidade do processo de acumulação de capital que acompanhou a transição do modelo econômico agrícola-exportador para o modelo de substituição de importações. O sistema financeiro, entretanto, apenas reproduziu e ratificou o padrão de crescimento desigual entre as regiões. Isto decorreu de dois motivos: (a) as regióes periféricas apresentaram maior preferência por liquidez; (b) o crédito oriundo de programas governamentais direcionados para as regióes periféricas foi, em grande parte, desviado para as regiões centrais.

Ainda para o caso brasileiro, Castro (2002) concluiu que o redepósito e a preferência pela liquidez estão associados ao grau de centralidade de regióes selecionadas. Quanto maior o número de pólos econômicos e a produtividade média do trabalho, maior a retenção de depósitos e menor a preferência pela liquidez de uma região. Essas diferenças são menos acentuadas em períodos de incerteza econômica. A região sob influência econômica do município de São Paulo foi caracterizada por maior capacidade de redepósito e menor preferência pela liquidez.

\subsection{Efeito Regionalmente Diferenciado de Condições Monetárias e Financeiras}

Alguns estudos consideram que a oferta de moeda e crédito em uma economia nacional distribui-se uniformemente entre suas regiôes componentes e o que poderia variar seriam seus efeitos sobre a atividade econômica regional. Para os Estados Unidos, evidências sobre variações regionais de crescimento econômico foram apresentadas por Carlino e Sill (2000) e por Evans e Karras (1996).

Beare (1976) produziu um modelo no qual o efeito da política monetária sobre a renda de cada regiáo depende da elasticidade-renda da demanda pelos produtos da região. 
Kozlowski (1991), por sua vez, ressalta a importância da taxa de juros praticada no âmbito nacional para a determinação dos ciclos econômicos regionais. Loo e Lastrapes (1988) apresentam um modelo no qual choques de oferta de moeda afetam diferentemente o produto de setores econômicos distintos (agricultura, mineração, indústria mecânica, telecomunicações etc.) e, por consequiência, têm diferentes impactos sobre regiốes de composição econômica setorial distinta.

Carlino e DeFina (1999), utilizando modelo VAR, verificaram que a renda pessoal real em cada Estado que compõe os Estados Unidos da América responde de forma diferenciada ao nível da taxa de juros praticada pelo Federal Reserve. Diferenças foram identificadas na defasagem e na magnitude da resposta da economia de cada Estado às inovações da política monetária. Verificou-se também que alguns Estados apresentam respostas diferentes daquelas da região em que estão inseridos. Quanto à composição econômica setorial de cada Estado, verificou-se que a sensibilidade da renda pessoal real de um Estado relativamente às variações da taxa de juros eleva-se com o aumento da participação dos setores de construção e de bens de consumo duráveis na renda desse Estado e com a diminuição da participação dos setores de indústria extrativa e de serviços financeiros.

Kouparitsas (2001) mostra como regiões dos Estados Unidos respondem diferentemente a choques econômicos diversos, inclusive monetários, concluindo que aquele país desvia-se significativamente do conceito de área monetária ótima concebido originalmente por Mundell (1961).

\section{AS PROPRIEDADES DOS CICLOS REGIONAIS BRASILEIROS: UMA VISÃO GERAL}

Uma forma simples e preliminar de analisar o comportamento regional dos ciclos é a partir da construção das correlações dos ciclos regionais. Correlação elevada entre os produtos de cada região evidencia que elas estão sujeitas a choques comuns e apresentam respostas similares a esses choques. Correlação reduzida indica que as regiões estão sujeitas a choques idiossincráticos e/ou respondem diversamente a choques comuns.

Séries de produto agregado de cada região foram submetidas a uma análise de correlação contemporânea e também defasada em um período. As séries foram obtidas de Azzoni (1997) e Azzoni e Barossi-Filho (2002), do IPEA e do IBGE e estão em 
base anual, estendendo-se de 1947 a 2000. ${ }^{1}$ As séries foram submetidas ao filtro Hoddrick-Prescott. $^{2}$

Os resultados são apresentados na Tabela 1. A correlação contemporânea entre o produto de cada região e o produto nacional demonstrou ser bastante variável. A região Norte apresentou a menor correlação $(0,37)$, enquanto a região Sudeste apresentou a maior $(0,89)$. As medidas de correlação entre produtos das regiões entre si também foram bastante variáveis. As maiores correlações foram aquelas envolvendo as regiões Sul, Sudeste e Centro-Oeste. A correlação entre os produtos das regiões Sudeste e Centro-Oeste, por exemplo, foi de 0,79. As menores correlações inter-regionais foram as referentes à região Norte. A menor correlação inter-regional foi de 0,29 entre as regiôes Norte e Sul

O painel inferior da Tabela 1 apresenta as correlações das flutuações regionais defasadas em um período. A diagonal principal desse painel registra medidas de persistência das flutuações regionais. A persistência regional dos ciclos do produto foi inferior à nacional em todas as regiões. A persistência das flutuações regionais é menor na região Norte e maior nas regiões Sudeste e Nordeste, que são aquelas que mais se aproximam da apresentada pelo agregado.

\section{TABELA I - COMOVEMENTS DOS CICLOS REGIONAIS}

\section{A. Correlação Contemporânea}

\begin{tabular}{lrrrrrr} 
& \multicolumn{7}{c}{ Renda no Períodot } \\
\cline { 2 - 7 } Renda no Período t & BRA & CO & NE & N & SE & S \\
\hline Brasil (BRA) & 1 & & & & & \\
Centro-Oeste (CO) & 0.81 & 1 & & & & \\
Nordeste (NE) & 0.61 & 0.42 & 1 & & & \\
Norte (N) & 0.37 & 0.40 & 0.40 & 1 & \\
Sudeste (SE) & 0.89 & 0.79 & 0.52 & 0.38 & 1 \\
Sul (S) & 0.59 & 0.65 & 0.38 & 0.29 & 0.72 & 1 \\
\hline
\end{tabular}

\section{B. Correlação Defasada}

Renda no Período $t+1$

\begin{tabular}{lclllll}
\cline { 2 - 7 } Renda no Período t & BRA & CO & NE & N & SE & S \\
\hline Brasil (BRA) & 0.75 & 0.63 & 0.53 & 0.26 & 0.69 & 0.42 \\
Centro-Oeste (CO) & 0.43 & 0.53 & 0.46 & 0.34 & 0.33 & 0.41 \\
Nordeste (NE) & 0.43 & 0.31 & 0.63 & 0.42 & 0.43 & 0.31 \\
Norte (N) & 0.31 & 0.21 & 0.23 & 0.46 & 0.19 & 0.04 \\
Sudeste (SE) & 0.73 & 0.54 & 0.61 & 0.55 & 0.63 & 0.45 \\
Sul (S) & 0.47 & 0.45 & 0.23 & 0.19 & 0.58 & 0.57 \\
\hline
\end{tabular}

1 Nesse sentido, embora não seja ideal o uso de dados anuais para se avaliar fenômenos de curto prazo, a limitação de dados para o Brasil não possibilita uma consideração com menor periodicidade.

2 Como consequiência, as séries se tornaram estacionárias. 
A correlação defasada permite identificar as regiões líderes, aquelas que antecipam os ciclos do produto no Brasil, e as regiões seguidoras, aquelas cujas flutuações são conseqüência dos ciclos do produto nacional. Observa-se que as regiões Sul e Sudeste apresentam correlações com o produto nacional no período seguinte (respectivamente 0,47 e 0,73$)$ maiores que as com o produto nacional no período anterior $(0,42 \mathrm{e}$ 0,69), ao contrário das demais regiões. Assim, pode-se concluir que as regiões Sul e Sudeste originam os ciclos de produto que se disseminam pelas demais regióes, ou seja, são líderes. Particularmente quanto à região Sudeste, observa-se que a correlação do produto dessa região com os produtos das demais regióes no período seguinte são as maiores correlações regionais defasadas obtidas, sugerindo que o ciclo do produto da região Sudeste antecipa e influencia os das demais regiões.

De um modo geral, tais resultados sugerem que as regióes brasileiras não apresentam fontes e/ou respostas comuns de distúrbios. Entretanto, tal abordagem fornece apenas uma evidência superficial de tal assertiva, de modo que não se poder afirmar se o Brasil constitui ou não uma área monetária ótima. Uma fraqueza óbvia deste tipo de metodologia é o não fornecimento de uma comparação concreta das fontes de distúrbios ou respostas entre regiões. Em vista disto, a análise empírica que se segue busca encontrar resultados que possibilitem que tal comparação seja feita.

\section{METODOLOGLA}

Uma forma de tentar resolver as limitações da análise de correlações simples é recorrer ao uso de um vetor auto-regressivo (VAR), de modo que com as restrições apropriadas dos parâmetros pode-se identificar fontes e respostas comuns e idiossincráticas às flutuações regionais. Nesse sentido, utiliza-se uma variante do modelo DYMIMIC (general dynamic multiple indicator-multiple cause), de Watson e Engle (1983), seguindo a sugestão de Kouparitsas (2001), que recorre a tal abordagem na análise dos ciclos regionais nos Estados Unidos.

\subsection{O Modelo Empírico}

A fim de identificar os componentes dos ciclos regionais assume-se inicialmente que o ciclo do produto real da região $i$ no período $t, y_{i t}$, é composto de dois componentes não-observados, um componente comum a todas as regiões, $x_{t}$, e um componente idiossincrático a cada região, $x_{i t}$. Neste sentido, cada região apresenta uma sensitividade distinta do componente comum, de acordo com o parâmetro $\gamma_{i}$, de tal forma que as flutuações regionais são dadas por: 


$$
y_{i t}=\gamma_{i t} x_{t}+x_{i t}
$$

para $i=1, \ldots, 5$.

Assim sendo, se as regiões brasileiras não apresentarem componente idiossincrático $x_{i t}$, então a renda regional, $y_{i t}$, irá variar sempre em termos perfeitamente proporcionais ao componente comum $x_{t}$, de forma que suas flutuações serão perfeitamente correlacionadas com as do produto agregado, satisfazendo os critérios de área monetária ótima.

Complementarmente, são inseridas no modelo duas fontes de choques comuns entre regiões, um nominal, o estoque de moeda, ${ }^{3}$ e outro real, cuja proxy aqui considerada se refere ao preço do petróleo. Tais variáveis, além de promoverem uma melhoria na acurácia das estimações, visam fornecer uma expansão do leque de explicações dos ciclos regionais, possibilitando, por exemplo, uma visualização de uma possível assimetria dos choques de política monetária sobre as regiões.

Desta forma, as séries usadas são divididas em séries de variáveis comuns às regiões e idiossincráticas. As comuns incluem $x_{t}$, o indicador de política monetária, $m_{t}$, e o preço relativo dos combustíveis $p_{t}$, enquanto que os componentes idiossincráticos são os $x_{i t}$.

Neste contexto, a identificação dos choques é feita a partir de uma abordagem VAR sobre a identificação de choques nos Estados Unidos, buscando seguir, aqui, Christiano, Eichenbaum e Evans (1994), ou seja, tratando as variáveis de renda regional de modo similar às variáveis macroeconômicas agregadas de tal estudo.

Mais especificamente, os componentes comuns da renda formam um modelo de comportamento dinâmico de um vetor 3 X l,

$$
Z_{t}=\left[p_{t}, x_{t}, m_{t}\right]^{\prime}
$$

A dinâmica de $Z_{t}$ é então representada pelo VAR,

$$
A Z_{t}=B(L) Z_{t-1}+e_{t}
$$

Em que $A$ é uma matrix $3 \times 3$ de coeficientes que descreve a correlação contemporânea entre as variáveis; $B(L)$ é uma matriz $3 \times 3$ de polinômios no operador de defasagem $L$ e $e_{t}=\left[\varepsilon_{p t}, \varepsilon_{x t}, \varepsilon_{m t}\right]$ é um vetor $3 \mathrm{X} 1$ de distúrbios estruturais ortogonais.

3 Embora a taxa de juros de curto prazo seja mais utilizada como proxy para política monetária para o Brasil, utilizou-se a série de estoque de moeda por haver uma série única para todo o período, e utilizou-se o M2 para calcular o saldo monetário real a fim de se minimizar as variaçóes bruscas observadas da demanda por moeda no período de alta inflação 
A fim de identificar os elementos de $e_{t}$, uma estrutura adicional precisa ser especificada para $A$. Assim, seguindo Christiano et al., $A$ é restrito a uma matriz triangular inferior, com números 1 ao longo da diagonal. A implementação de tal hipótese tem representatividade direta na ordem assumida dos choques, em que fica predisposto que inovações em $p_{t}$ têm efeitos contemporâneos em $x_{t} \mathrm{e} m_{t}$; inovações em $x_{t}$ têm efeitos contemporâneos em $m_{t}$ e defasados em $p_{t}$; e inovações em $m_{t}$ têm efeitos defasados em $p_{t}$ e $x_{t}$. Desta forma, a hipótese fundamental de tal modelo é que a escolha de política monetária tanto afeta como reage à economia. Tal implementação ocorre pela construção de uma regra de feedback das autoridades monetárias, escrita como uma função linear, $\psi$, definida sobre um vetor, $\Omega$, de variáveis observadas até o período $t$. Logo, a política monetária é descrita completamente por:

$$
m_{t}=\psi\left(\Omega_{t}\right)+A_{33} \varepsilon_{m t}
$$

onde $\psi\left(\Omega_{t}\right)$ se torna igual a $-a_{31} p_{t}-a_{32} x_{t}+b_{3} \cdot Z_{t-1}$ e equivale à terceira linha da matriz $B(L)$ acrescida de mais dois termos $\left(-a_{31} p_{t}-a_{32} x_{t}\right)$. Desta forma, um choque exógeno na política monetária $\varepsilon_{m t}$ não afeta contemporaneamente valores das demais variáveis comuns às regióes, mas apenas seu valores defasados.

O bloco idiossincrático, por sua vez, foca o comportamento dinâmico de um vetor $5 \mathrm{X} 1$ de componentes idiossincráticos da renda regional:

$$
X_{t}=\left[x_{1 t}, x_{2 t}, \ldots, x_{5 t}\right]
$$

Nesse contexto, as variáveis idiossincráticas são afetadas de forma similar às variáveis comuns ao defrontar-se com choques nos preços de combustíveis e na política monetária. Em particular, inovações em $p_{t}$ têm efeitos contemporâneos em $x_{i t}$, enquanto inovações em $m_{t}$ têm efeitos defasados em $x_{i t}$. Por outro lado, em contraste com o componente comum, inovaçôes no componente idiossincrático não têm efeitos nos preços do combustível ou na política monetária, de forma que é assumido que tanto os preços dos combustíveis como a política monetária reagem apenas a choques agregados.

Sob tais hipóteses, a dinâmica do componente idiossincrático da região $i$ é explicada por:

$$
x_{i t}=D_{i}(L) x_{i t-1}+E_{i}(L) W_{t}+\varepsilon_{i t}
$$

para todo $i$, onde $W_{t}=\left[p_{t}, m_{t}\right]^{\prime}$ e $\varepsilon_{\text {it }}$ são ortogonais. 
Assim sendo, tal modelo nos fornece a possibilidade de dividir as séries regionais entre choques comuns observados (choques monetário e sobre o preço dos combustíveis) e não observados, bem como a construção das séries de choques idiossincráticos de cada região.

\subsection{Estratégia de Estimação}

As equações (1)-(6) fornecem uma variação de um modelo DYMIMIC (dynamic multiple indicator-multiple canse) que pode ser estimado usando o algoritmo recursivo EM de Watson e Engle (1983).

Neste sentido, enquanto o choque comum é dado pelos resíduos da equação de produto agregado do sistema VAR (3), os componentes idiossincráticos são obtidos a partir a aplicação do filtro de Kalman em um modelo de representação de estado-espaço, dado, seguindo o sistema (1) a (6), por:

Equação de medida:

$\left[\begin{array}{ll}I_{5 X 5} & 0 \\ \mathbf{O}_{2 X 5} & \tilde{A}\end{array}\right]\left[\begin{array}{c}Y_{t} \\ W_{t}\end{array}\right]=\left[\begin{array}{ll}\mathbf{O}_{5 X 7} & \\ \mathbf{O}_{2 X 5} & B(L)\end{array}\right]\left[\begin{array}{c}Y_{t-1} \\ W_{t-1}\end{array}\right]+\left[\begin{array}{cc}I_{5 X 5} & \Gamma \\ \mathbf{O}_{2 X 5} & \tilde{C}(L)\end{array}\right] \tilde{X}_{t}+\left[\begin{array}{c}\mathbf{O}_{5 X 1} \\ \varepsilon_{p t} \\ \varepsilon_{p m}\end{array}\right]$

Equação de transição:

$$
\tilde{X}_{t}=\left[\begin{array}{cc}
D(L) & 0 \\
0 & D_{x}(L)
\end{array}\right] \tilde{X}_{t-1}+\left[\begin{array}{c}
E(L) \\
E_{x}(L)
\end{array}\right] W_{t}+\left[\begin{array}{c}
\omega_{t} \\
\left.\varepsilon_{x t}\right)
\end{array}\right]
$$

onde $\left.Y_{t}=\left[y_{1 t}, y_{2 t}, \ldots, y_{5 t}\right\}\right]^{\prime}, \Gamma=\left[\gamma_{1}, \gamma_{2}, \ldots, \gamma_{5}\right]^{\prime}$ e $\tilde{X}_{t}=\left[X_{t}^{\prime}, x_{t}\right]^{\prime}$.

Identificando-se os parâmetros que governam o componente comum, respostas idiossincráticas e distúrbios estruturais requerem uma normalização adicional das restrições. A variância do componente estrutural de distúrbio do componente comum das rendas regionais é identificada pela normalização de $\gamma_{i}$ para 1 de uma das cinco regiões. As respostas idiossincráticas da renda regional a choques não-antecipados ao preço do petróleo e à política monetária são identificadas pela normalização das respostas de uma região que deve ser a mesma resposta do componente comum. Em outras palavras, a resposta idiossincrática é identificada pela restrição $E_{i}(L)=0$ para uma das cinco regiões. A região escolhida para sofrer tal normalização é a região Sudeste, uma vez que é a região que apresenta maior correlação com a renda nacional agregada, e cuja amplitude é muito próxima das freqüências dos ciclos econômicos do Brasil. 


\subsection{Decomposição da Variância}

Um objetivo deste artigo é fazer a decomposição da variância dos ciclos regionais de acordo com as diversas fontes comuns e idiossincráticas de inovação. Isto é realizado por meio de um filtro $G(L)$, que permite mapear as covariâncias dos componentes dos ciclos regionais a partir da covariância dos ciclos regionais. A forma precisa do filtro é $G(L)=B P(L) /(1-L)$, onde $B P(L)$ é a aplicação de um filtro Band-Pass tipo Baxter-King aos ciclos regionais e $L$ é o operador de defasagem. Para se mapear a freqüência dos ciclos regionais para a utilização do filtro utilizou-se a análise espectral de Fourier.

\section{OS RESULTADOS EMPÍRICOS}

O modelo empírico é estimado para o período 1947-2000, com dados anuais cujas fontes são o IPEA, a EIA, o IBGE e o trabalho de Azzoni e Barossi-Filho (2002). Enquanto para todos os ciclos regionais os dados são estacionários, uma vez que foram submetidos ao filtro $\mathrm{HP}$, as séries de saldo monetário real e do preço do petróleo ${ }^{4}$ para o período apresentam raiz unitária, o que pode ser observado na Tabela $2,{ }^{5}$ de modo que é necessária a utilização da primeira-diferença de tais séries para se evitar resultados espúrios.

As estimaçóes do modelo possibilitam um estudo adequado de todos os critérios de área monetária ótima de Mundell (1961) bem como uma análise sobre o comportamento dos ciclos econômicos sobre as regiões brasileiras. Neste sentido, o modelo possibilita uma caracterização tanto das fontes dos ciclos regionais como do comportamento das flutuações da renda das regiões diante de choques comuns e idiossincráticos.

4 As séries de preço do petróleo são de preço real, seguindo o original da fonte.

5 Vale notar que o único caso em que não é observada raiz unitária para as variáveis em nível é para a variável preço do petróleo e apenas no teste KPSS. 
TABELA 2 - TESTES DE RAIZ UNITÁRIA

\begin{tabular}{lcc}
\hline Teste ADF & & \\
\hline Variável & Nível & primeira diferença \\
\hline OIL & -2.055 .524 & -5.958 .677 \\
M/P & -1.703 .708 & -6.980 .158 \\
Valores Críticos & & \\
$1 \%$ & -4.137 .279 & -4.140 .858 \\
$5 \%$ & -3.495 .295 & -3.496 .960 \\
$10 \%$ & -3.176 .618 & -3.177 .579 \\
\hline Teste PP & & \\
\hline Variável & Nível & -5.867 .135 \\
\hline OIL & -2.243 .256 & -6.997 .884 \\
M/P & 7.264 .904 & \\
Valores Críticos & & -4.140 .858 \\
$1 \%$ & -4.137 .279 & -3.496 .960 \\
$5 \%$ & -3.495 .295 & -3.177 .579 \\
$10 \%$ & -3.176 .618 & \\
\hline Teste KPSS & & primeira diferença \\
\hline Variável & Nível & 0.054116 \\
\hline OIL & 0.099686 & 0.080063 \\
M/P & 0.190659 & \\
Valores Críticos & & 0.216000 \\
$1 \%$ & 0.216000 & 0.146000 \\
$5 \%$ & 0.146000 & 0.119000 \\
$10 \%$ & 0.119000 &
\end{tabular}

Uma forma de avaliar a importância dos choques comuns e idiossincráticos para cada região é analisar a volatilidade de tais choques. Neste aspecto, a Tabela 3 reporta a volatilidade dos choques estimados e um teste $\chi^{2}$ para comparar a volatilidade de cada tipo de choque, na qual é possível observar que em todas as regiões no Brasil os choques idiossincráticos são estatisticamente mais voláteis que os choques comuns. Isto indica que os choques idiossincráticos são um componente importante de variação das regiões brasileiras. Pode-se observar, sobretudo, que a volatilidade dos choques idiossincráticos na região Sudeste é estatisticamente mais volátil que a de qualquer outra região, o que, com tudo o mais constante, sugere que os choques específicos são a fonte mais importante de variação na região Sudeste que nas demais regiões. Tal resultado faz sentido, tendo em vista que a região Sudeste foi a responsável por mais de $75 \%$ do PIB industrial do Brasil em todo o período analisado. Sob este aspecto, as condiçôes (i) e (ii) da área monetária ótima podem ser rejeitadas a princípio, uma vez que fica constatado que as regióes estão expostas a fontes diferentes de distúrbios econômicos (os choques não são comuns) e que a importância relativa de tais choques não é similar entre as regiões (os choques não são simétricos). Sob esta ótica, 
decomposições dos erros de previsão um período à frente entre os vários choques do modelo fornecem um quadro mais completo da importância relativa dos choques. Tais decomposições indicam que as parcelas dos erros de previsão atribuídos a choques idiossincráticos são sensivelmente maiores que aos choques comuns em todas as regiões (Tabela 5 , item $\mathrm{A}$ ).

\section{TABELA 3 - VOLATILIDADE ESTIMADA DOS CHOQUES ESTRUTURAIS}

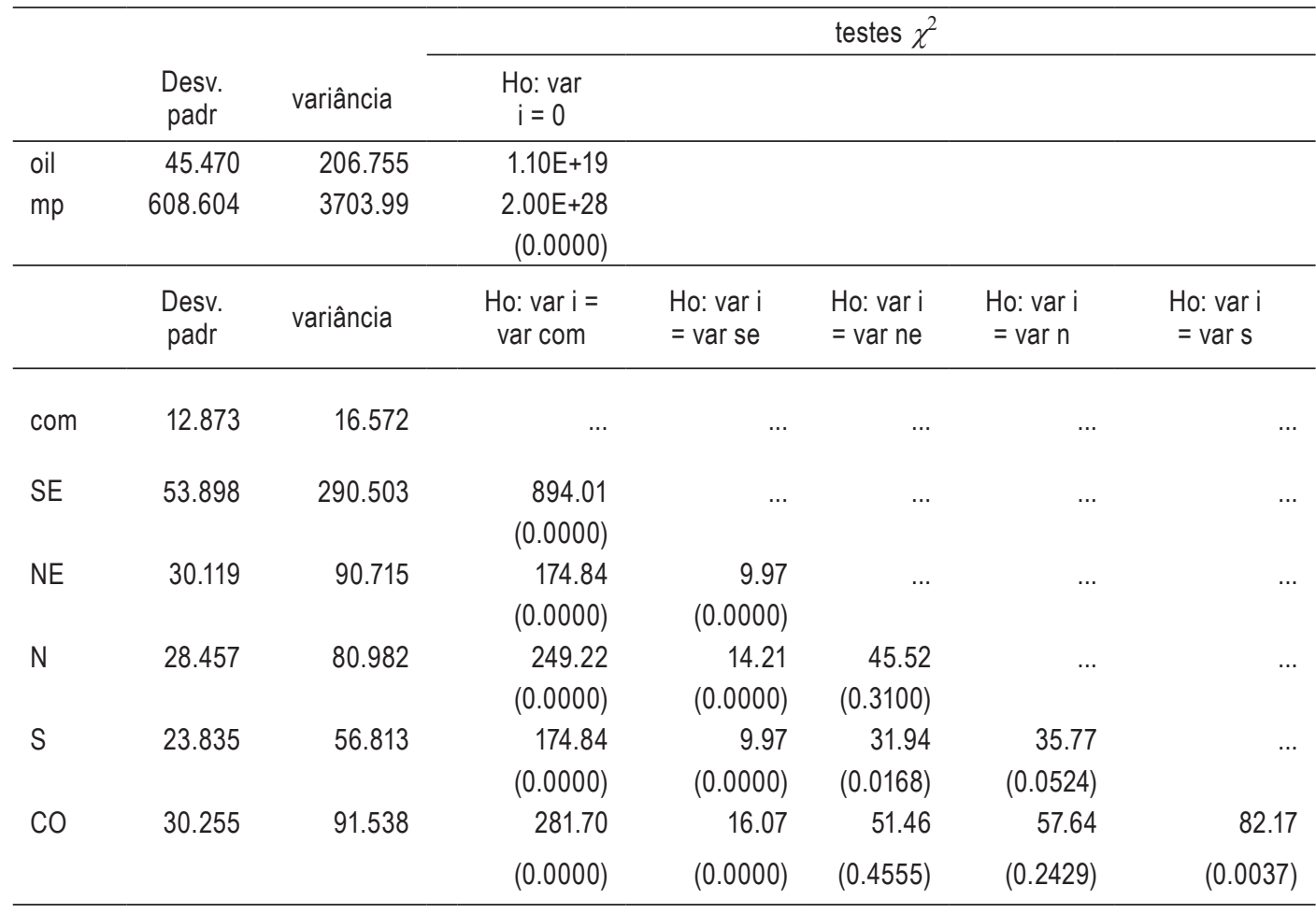

OBS: ( ) contém as probabilidades; com significa choques comuns na renda; oil, é a primeira diferença do preço do petróleo; mp é a primeira diferença dos saldos monetários reais; e SE, NE, N, S, CO, os choques idiossincráticos as regióes Sudeste, Nordeste, Norte, Sul e Centro-Oeste, respectivamente.

Pode-se avaliar se a sensitividade dos choques comuns é igual para todas as regiões ao se realizar um teste de Wald para observar se os coeficientes $\gamma_{\mathrm{i}}$ são iguais para todas as regiões. Tais testes são apresentados na Tabela 4 , e, como pode ser observado, embora a região Sudeste apresente menor sensitividade a choques comuns que as demais regiões, tal diferença não é estatisticamente significante. Assim, não é possível se rejeitar que todas as regióes respondem, de forma similar, a choques comuns, de modo que a condição (iii) da área monetária ótima se verifica para as regiões brasileiras. 
TABELA 4 - SENSITIVIDADE AOS CHOQUES COMUNS

\begin{tabular}{|c|c|c|c|c|c|}
\hline \multirow[t]{2}{*}{ região i } & \multirow[t]{2}{*}{$\gamma_{\mathrm{i}} / \gamma_{\mathrm{se}}$} & \multicolumn{4}{|c|}{ testes $\chi^{2}$} \\
\hline & & $\mathrm{Ho}=\gamma_{\mathrm{se}}=\gamma_{\mathrm{i}}$ & $\mathrm{Ho}=\gamma_{\mathrm{ne}}=\gamma_{\mathrm{i}}$ & Ho $=\gamma_{n}=\gamma_{i}$ & $\mathrm{Ho}=\gamma_{\mathrm{s}}=\gamma_{\mathrm{i}}$ \\
\hline SE & 1.00 & $\ldots$ & $\ldots$ & $\ldots$ & $\ldots$ \\
\hline NE & 1.08 & $\begin{array}{r}0.0000586 \\
(0.9939)\end{array}$ & $\ldots$ & $\ldots$ & $\ldots$ \\
\hline N & 1.09 & $\begin{array}{r}0.000234 \\
(0.9878)\end{array}$ & $\begin{array}{r}1.97 \mathrm{E}-07 \\
(0.9996)\end{array}$ & $\ldots$ & $\ldots$ \\
\hline S & 1.03 & $\begin{array}{r}3.33 \mathrm{E}-06 \\
(0.9985)\end{array}$ & $\begin{array}{r}1.92 \mathrm{E}-05 \\
(0.9995)\end{array}$ & $\begin{array}{r}1.41 \mathrm{E}-05 \\
(0.9970)\end{array}$ & $\ldots$ \\
\hline $\mathrm{CO}$ & 1.30 & $\begin{array}{r}0.000926 \\
(0.9757)\end{array}$ & $\begin{array}{r}0.000934 \\
(0.9756)\end{array}$ & $\begin{array}{r}0.000595 \\
(0.9805)\end{array}$ & $\begin{array}{r}0.001106 \\
(0.9735)\end{array}$ \\
\hline
\end{tabular}

OBS: ( ) contém as probabilidades de Ho estar certo; SE, NE, N, S, e CO simbolizam as regiões Sudeste, Nordeste, Norte, Sul e Centro-Oeste, respectivamente.

Por fim, para se avaliar a quarta condição de área monetária ótima as funções de resposta a impulso para cada região, dados choques nas variáveis comuns e idiossincráticas, fornecem o comportamento da resposta dos ciclos regionais ao longo do tempo. Tais respostas são apresentadas nas Figuras l a 5 (anexas). Em tais figuras fica claro que o ciclo regional não tende a se ajustar rapidamente quando sujeitas a um choque específico. Na região Sudeste esse tempo é de cerca de seis anos, na Centro Oeste, de cerca de oito anos, na Sul, de aproximadamente dez anos e, na Norte, mais de dez anos. A única região onde o ciclo se ajusta rapidamente é na região Nordeste. Por outro lado, em todas as regiões um choque comum não levou a fortes variaçôes no produto de curto prazo. Tais resultados implicam que a quarta condição de área monetária ótima para as regiões brasileiras também pode ser rejeitada. Por fim, fica claro que em todas as regiôes as funçóes de resposta a impulso apresentam os sinais esperados e tendem à convergência das respostas.

Dada a grande importância do componente idiossincrático para se explicar as flutuações das rendas regionais, as funções de resposta a impulsos dos componentes idiossincráticos são apresentadas nas Figuras 6 a 10 (anexas). Nestas figuras é possível observar que um choque idiossincrático a uma região tem um impacto persistente sobre cerca de 5 a 6 anos na maioria das regiões. Neste aspecto, podemos imaginar, por exemplo, que um choque tecnológico em uma região tem um impacto sobre o ciclo desta região de cerca de 5 anos, o mesmo ocorrendo com outros choques idiossincráticos, como seca, ou outros eventos presentes apenas em uma das regiôes.

Embora as inferências sobre a significância das respostas não tenham sido elevadas na maioria dos casos observados nas Figuras 1 a 10, isto já era esperado, pois, na prática, 
isto é muito comum e não representa, necessariamente, insignificância dos resultados. Em relação a este aspecto, lemos em Hamilton (1994, p. 339-40) que: "in practice, the standard errors for dynamic inferences base don VARs often turn out to be disappointingly large. Althoug a VAR imposes few restrictions on the dynamics, the cost of this generality is that the inferences draw are not precise."

Complementarmente, é possível realizar-se uma decomposição de variância dos ciclos regionais cujos resultados, para um horizonte de dez anos, são apresentados na Tabela 5. Em todas as regiões pôde-se observar que os choques idiossincráticos são mais relevantes para a explicação dos ciclos que os choques comuns. Neste sentido, os choques idiossincráticos representaram $66,96 \%$ a $80,47 \%$ da explicação dos ciclos das regióes. Além disso, ao se realizar um teste $\chi^{2}$ pôde-se verificar que se pode rejeitar o fato de que os choques comuns somados são a fonte dos ciclos regionais. Tais resultados impedem que as regióes sejam divididas em regiões "core" e "non-core".

\section{TABELA 5 - DECOMPOSIÇÃO DE VARIÂNCIA DOS CICLOS REGIONAIS}

\begin{tabular}{|c|c|c|c|c|c|}
\hline \multicolumn{6}{|l|}{ A. 1 período à frente } \\
\hline \multirow[t]{2}{*}{ Fonte de Inovação } & \multicolumn{5}{|c|}{ Variação Total Referente à Inovação } \\
\hline & SE & NE & $\mathrm{N}$ & $S$ & $\mathrm{CO}$ \\
\hline Choque de Oferta & 1.16 & 1.73 & 0.14 & 1.96 & 0.07 \\
\hline Política Monetária & 7.05 & 4.07 & 0.11 & 2.33 & 2.86 \\
\hline Componente Comum & 0.01 & 0.01 & 0.01 & 0.01 & 0.06 \\
\hline Total Comp. Comuns & 8.22 & 5.81 & 0.26 & 4.30 & 2.99 \\
\hline Comp. Idiossincrático & 91.78 & 94.19 & 99.74 & 95.70 & 97.01 \\
\hline Total & 100.00 & 100.00 & 100.00 & 100.00 & 100.00 \\
\hline \multicolumn{6}{|l|}{ B. 10 períodos à frente } \\
\hline \multirow[t]{2}{*}{ Fonte de Inovação } & \multicolumn{5}{|c|}{ Variação Total Referente à Inovação } \\
\hline & SE & $\mathrm{NE}$ & $\mathrm{N}$ & $S$ & $\mathrm{CO}$ \\
\hline Choque de Oferta & 18.02 & 17.42 & 4.36 & 8.44 & 5.97 \\
\hline Política Monetária & 7.90 & 3.55 & 0.18 & 1.93 & 2.46 \\
\hline Componente Comum & 3.60 & 12.07 & 14.99 & 17.41 & 12.79 \\
\hline Total Comp. Comuns & 29.52 & 33.04 & 19.53 & 27.78 & 21.22 \\
\hline Comp. Idiossincrático & 70.48 & 66.96 & 80.47 & 72.22 & 78.78 \\
\hline Total & 100.00 & 100.00 & 100.00 & 100.00 & 100.00 \\
\hline
\end{tabular}

No que se refere às respostas a choques de política monetária, nota-se que menos de $10 \%$ dos ciclos das regiões são causados pela política monetária. Ao mesmo tempo, observa-se que as respostas a choques monetários são fortemente assimétricas entre as regiões, de forma que é possível afirmar, com base na definição de política monetária ótima de Rotemberg e Woodford (1997), que cada região teria uma regra de política 
monetária ótima distinta, confirmando-se as predições da teoria como em Blinder e Mankiw (1984). Outrossim, uma vez verificado que uma política monetária ativa que visa afetar o produto significa perda de bem-estar no longo prazo em um ambiente de viscosidade de preços, como demonstrado por Mankiw (1986) e Ball e Romer (1990), fica claro que determinadas regiões tendem a ser constantemente prejudicadas por tais tipos de políticas monetária relativamente a outras regiões. Ao mesmo tempo, tais resultados poderiam ainda ser aplicados aos modelos teóricos de Duca e Van Hoose (1990) e Ahmed e Miller (1997), que demonstram que uma política monetária só pode ser estabilizadora para todos os setores se os choques a que estas estiverem sujeitas forem simétricos. Assim, as estimações apresentadas evidenciam que uma política monetária não é capaz de ser estabilizadora para todas as regiões brasileiras. É evidente que há vantagens em se usar uma única moeda para todas as regiões, tal como a diminuição de custos de transação comerciais e financeiros, de forma que as conclusões aqui expostas não visam à adoção de diferentes moedas para as regióes brasileiras, mas sim atentar para o fato de que uma política monetária ativa tem resultados distintos entre regiões, provocando impacto sobre a distribuição regional de renda.

\section{CONCLUSÕES}

O presente artigo buscou analisar a dinâmica de curto prazo das regiões brasileiras. Neste sentido, é utilizada uma variação do modelo DYMIMIC (general dynamic multiple indicator-multiple cause) a partir do algoritmo EM de Watson e Engle (1983) a fim de separar os ciclos regionais em componentes comuns a todas as séries e em componentes idiossincráticos, e a partir de tal resultado avaliar as respostas dos ciclos regionais a diferentes tipos de choques.

Assim, é demonstrado que as respostas da dinâmica de curto prazo das regiôes brasileiras variam drasticamente entre regiões. Das quatro condições de área monetária ótima sugeridas por Mundell (1961) apenas a terceira condição não pôde ser rejeitada para as regiões brasileiras. Ficou claro que as regiões respondem fortemente a choques idiossincráticos, sendo estes os principais causadores dos ciclos regionais, e que choques em uma política monetária têm respostas distintas entre regiões.

Uma conseqüência importante de tal resultado é a conclusão baseada nos modelos de Mankiw e Blinder (1984), Duca e Van Hoose (1990) e Ahmed e Miller (1997) de que cada região brasileira teria uma regra de política monetária ótima distinta, de modo que ao se escolher uma determinada política monetária está se escolhendo uma região como beneficiada com relação às demais. 


\section{REFERENCIAS}

Ahmed, H.; Miller, S. Monetary and exchange rate policy in multisectoral economies. Journal of Economics and Business, 49, p. 321-334, 1997.

Amado, A. Disparate regional development in Brazil: a monetary production approach. Aldershot: Ashgate, 1997. 360p.

Azzoni, C. R.; Barossi-Filho, M. A time series analysis of regional income convergence in Brazil. Anais do XXX Encontro Nacional da ANPEC, Nova Friburgo-RJ, 2002.

Ball, L.; Romer, D. Real rigidities and the non-neutrality of money. Review of Economic Studies, 57, p. 183-203, April 1990.

Beare, J. B. A monetarist model of regional business. Journal of Regional Science, v. 16, n. 1, p. 57-63, 1976.

Carlino, G.; DeFina, R. The differential effects of monetary policy: evidence from the U.S. states and regions. Journal of Regional Science 39, 1999.

Carlino, G.; Sill, K. Regional income fluctuations: common trends and common cycles. Federal Reserve Bank of Chicago. Working Paper 00-8, August 2000.

Castro, Cláudio Barra de. Moeda e espaço: os casos das áreas metropolitanas de São Paulo, Rio de Janeiro, Belo Horizonte, Curitiba, Salvador e suas áreas de polarização. 2002. Dissertação (Mestrado), CEDEPLAR-UFMG, Belo Horizonte.

Chick, V. Some scenarios for money in banking in the EC and their regional implications. In: Rima, I. H. (ed.), The political economy of global restructuring: economic organization as production. Cheltenham: Edward Elgar, 1993, v. 2: Trade and finance, p. 190-200.

Christiano, L. J.; Eichenbaum, M.; Evans, C. L. Identification and the effects of monetary policy shocks. Federal Reserve Bank of Chicago, Working Paper, n. 94-7, 1994.

D'Amico, N.; Parigi, G.; Trifilidis, M. I tassi d' interesse e la rischiosita degli impieghi bancari. In: BANCA D'ITALIA (ed), II sistema finnaziario nel mezzogiorno, special issue of the Contributi all' analisi economica. Rome: Banca d'Italia, 1990, p. 305-47.

Dow, S. C. The regional composition of the bank multipler process. Scottish Journal of Political Economy, v. 29, n.1, p. 22-44, 1982.

. Money and regional development. Studies in Political Economiy, v. 23, n. 2, p. 73-94, 1987.

. Financial markets and regional economic development: the Canadian experience. Aldershot: Averbury, 1990.

. The regional financial sector: a Scottish case study. Regional Studies, v. 26, n. 7, p. 619-631, 1992. 
Dow, S. C.; Rodriguez-Fuentes, C. J. Regional finance: a survey. Regional Studies, v. 31, n. 9, p. 903-20, 1997.

Duca, J.; Van Hoose, D. Optimal monetary policy in a multisector economy with an economywide money market. Journal of Economics and Business, 42, p. 253263, 1990.

Faini, R.; Galli, G.; Giannini, C. Finance and development: the case of southern Italy. In: Giovannini, A. (ed.), Finance and development: issues and experience. Cambridge: Cambridge University, 1993, p. 158-213.

Hamilton, J. Time series analysis. Princeton University Press, 1994.

Hutchinson, R. W.; McKillop, D. G. Regional financial sector models: an application to the Northern Ireland financial sector. Regional Studies, v. 24, n. 5, p. 421-31, 1991a.

. Financial intermediaries and financial markets: a United Kingdom regional perspective. Regional Studies, v. 25, n. 6, p. 543-54, December 1991.

Kouparitsas, $M$. Is the United States an optimum currency area? An empirical analysis of regional business cycles. Federal Reserve Bank of Chicago, Working Paper 2001-22, 2001.

Kozlowski, P. J. Integrating money into regional models of leading indicators. Review of Regional Studies, v. 21, n. 3, p. 235-48, 1991.

Loo, C. M.; Lastrapes, W. D. Identifying the effects of money supply shocks on industry-level output. Journal of Macroeconomics, v. 20, n. 3, p. 431-49, 1988.

Mankiw, G. Small menu costs and large business cycle: a macroeconomic model of monopoly. Quarterly Journal of Economics, 100, p. 529-37, May 1985.

Mankiw, G.; Blinder, A. Aggregation and stabilization policy in a multicontract economy. Journal of Monetary Economics, v. 13, n. 1, p. 67-86, January 1984.

Moore, C. L.; Hill, J. M. Interregional arbitrage and the supply of loanable funds. Journal of Regional Science, v. 22, n. 4, p. 499-512, 1982.

Moore, C. L.; Karaska, G. J.; Hill, J. M. The impact of the banking system on regional analyses. Regional Studies, v. 19, n. 1, p. 29-35, Feb. 1985.

Mundell, R. A. A theory of optimum currency areas. American Economic Review, v. 51, p. 657-665, 1961.

Roberts, R. B.; Fishkind, H. H. The role of monetary forces in regional economic activity: an econometric simulation analisys. Journal of Regional Science, v. 19, n. 1, p. 15-29, Feb. 1979.

Rotemberg, J.; Woodford, M. An optimization-based econometric framework for the evaluation of monetary policy. NBER Macroeconomics Anmual, p. 297-346, 1997.

Sims, C. Stickiness. Carnegie-Rochester Conference Series on Public Policy, v. 49, n. 1, p. 317-356, December 1998. 
Watson, M. W.; Engle, R. F. Alternative algorithms for the estimation of dynamic factor, MIMIC and varying coefficient models. Journal of Econometrics, v. 23, p. 385-400, 1983.

\section{ANEXO - FIGURAS}

\section{FIGURA 1 - RESPOSTAS DO PRODUTO DE CURTO PRAZO A IMPULSOS NA REGIÃO SUDESTE}

Response of CSE to IDSE

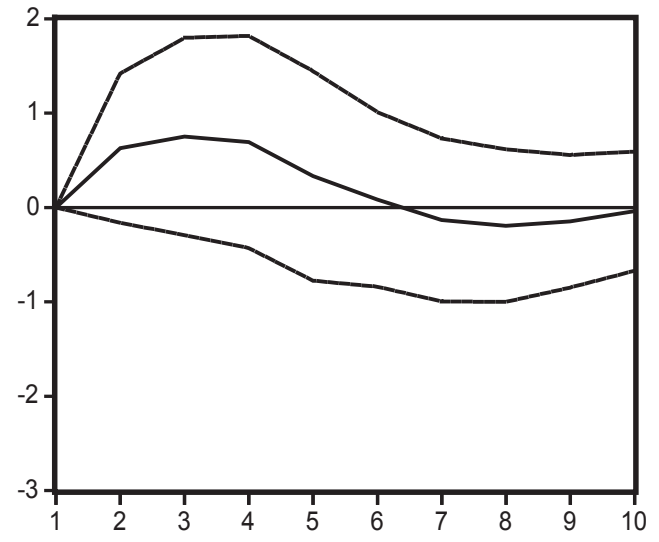

Response of CSE to OLL1

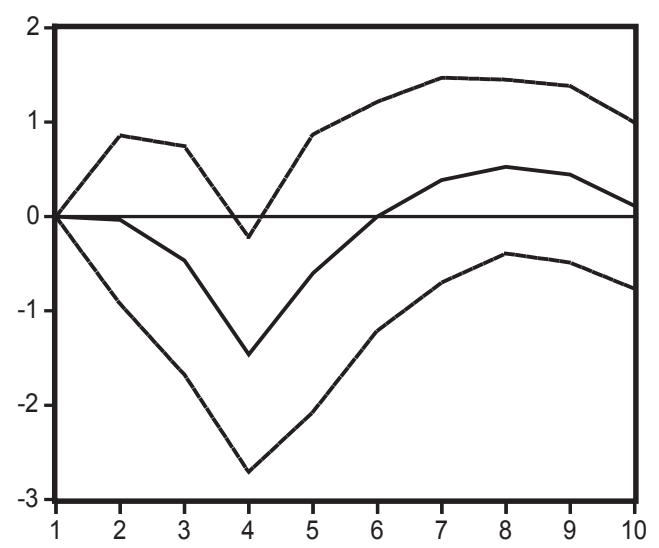

Response of CSE to COMON

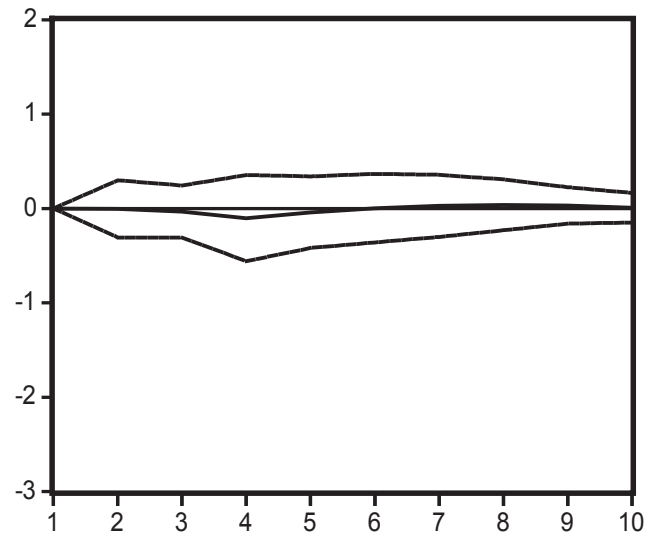

Response of CSE to MP1

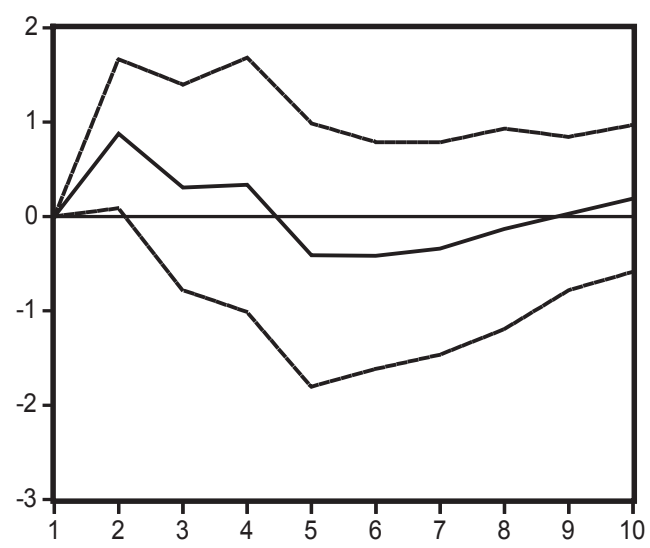


FIGURA 2 - RESPOSTAS DO PRODUTO DE CURTO PRAZO A IMPULSOS NA REGIÃO NORDESTE

Response of CNE to IDNE

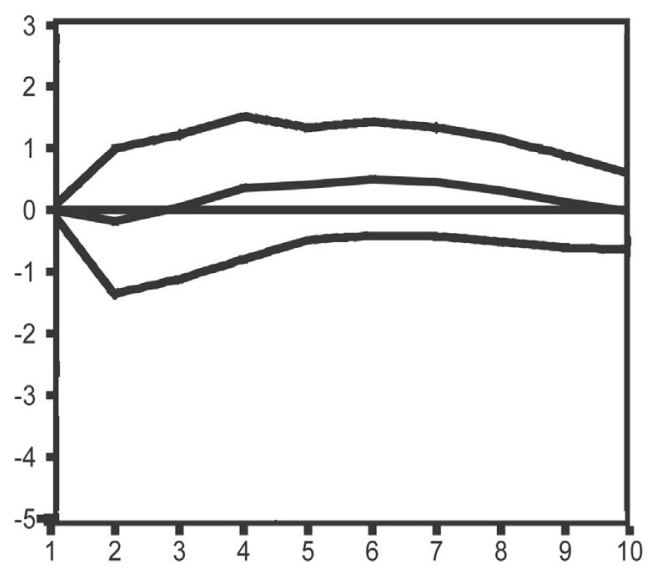

Response of CNE to OIL1

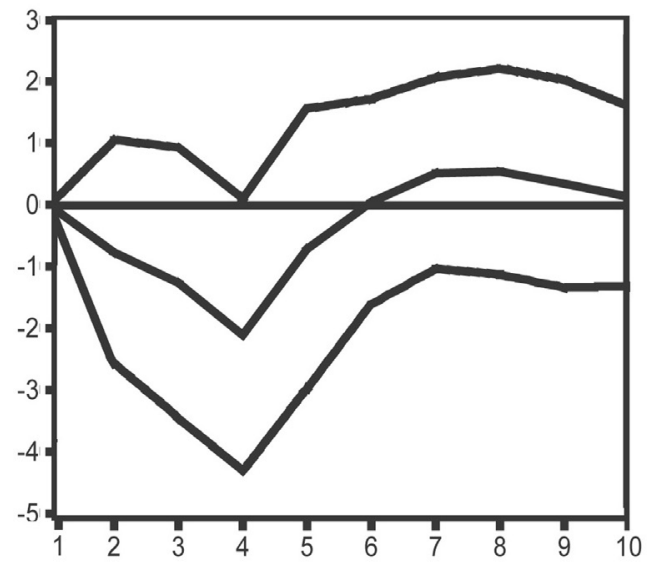

Response of CNE to COMON

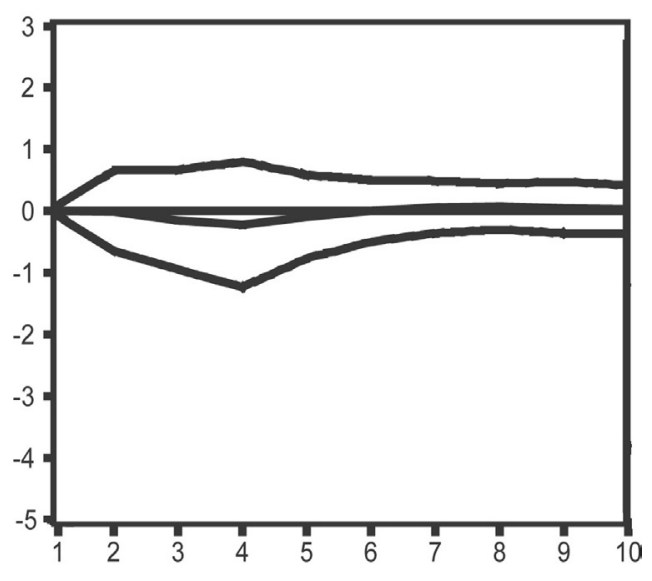

Response of CNE to MP1

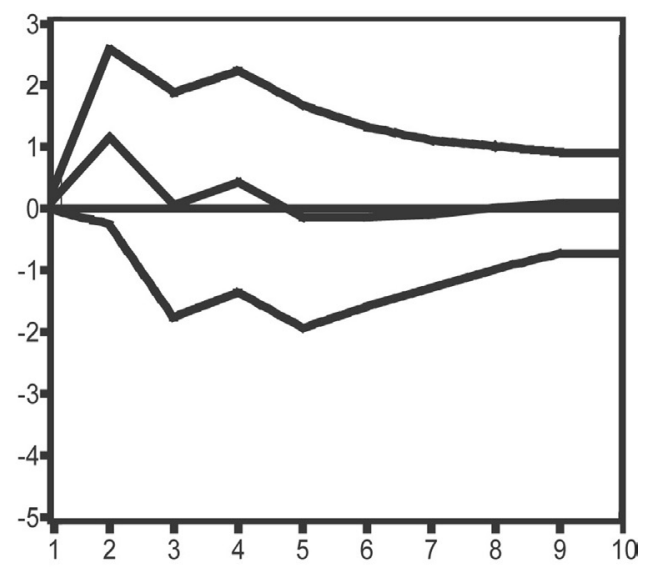


FIGURA 3 - RESPOSTAS DO PRODUTO DE CURTO PRAZO A IMPULSOS NA REGIÃO NORTE

Response of CN to IDN

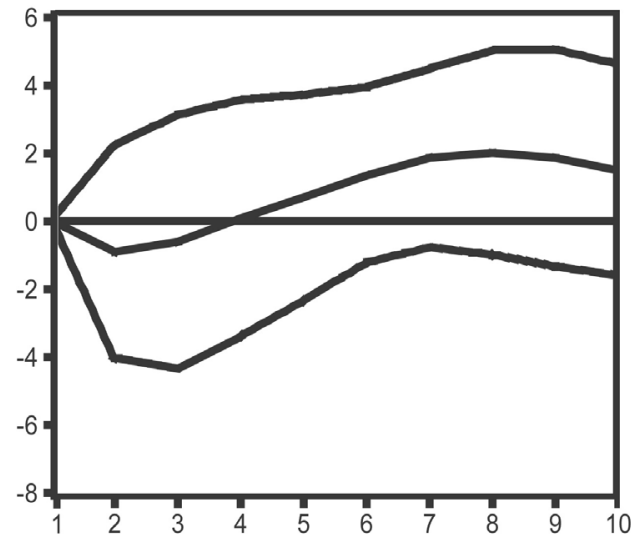

Response of CN to OIL1

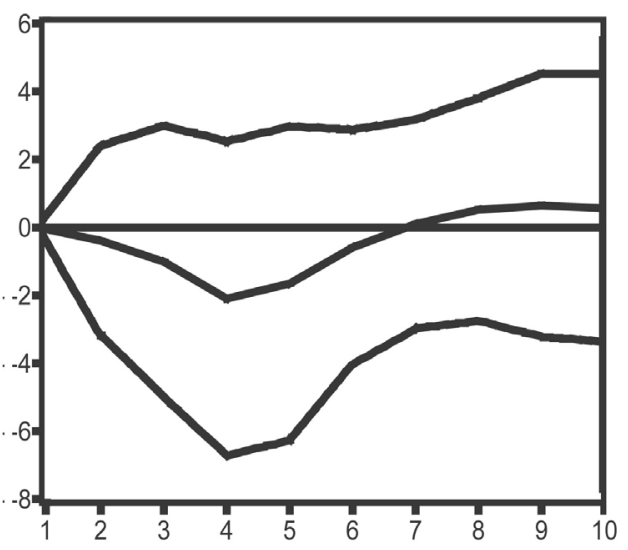

Response of CN to COMON

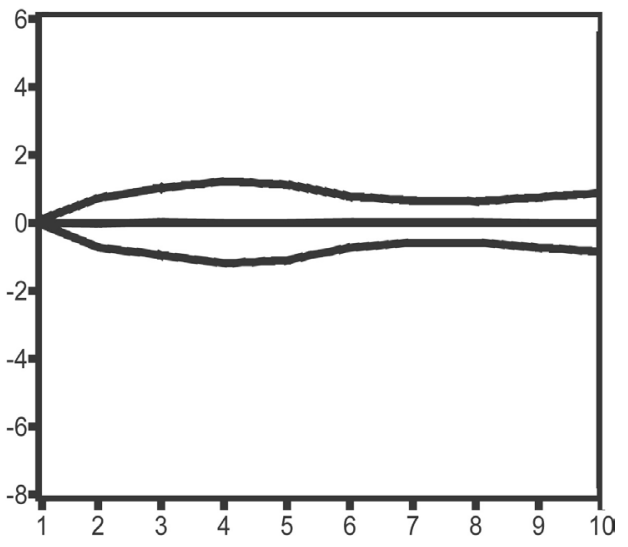

Response of CN to MP1

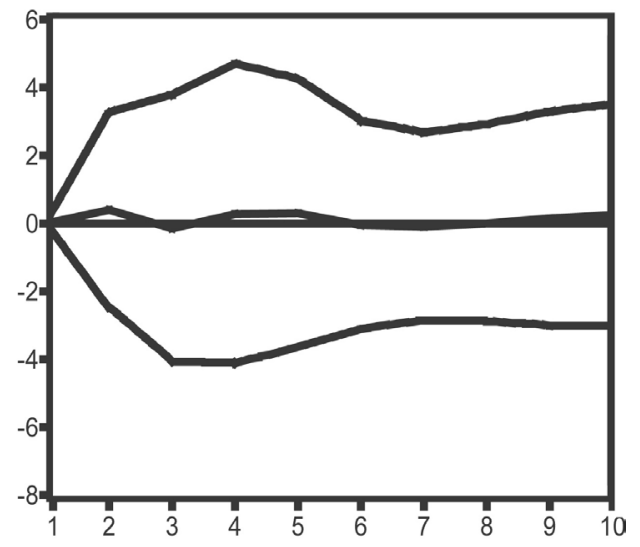


FIGURA 4 - RESPOSTAS DO PRODUTO DE CURTO PRAZO A IMPULSOS NA REGIÃO SUL

Response of CS to IDS

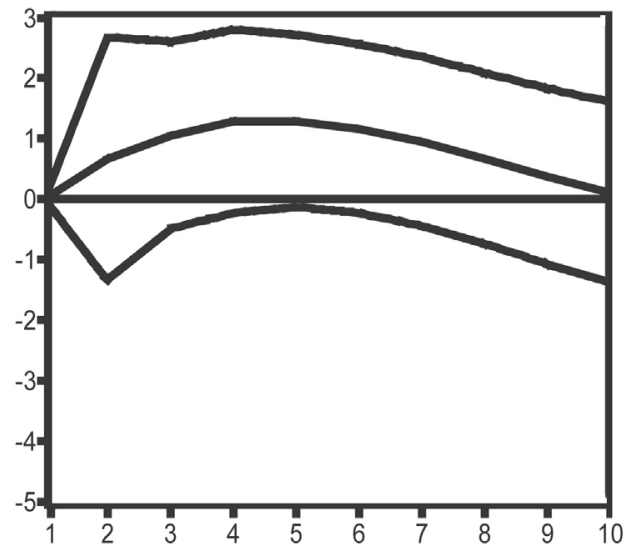

Response of CS to OIL1

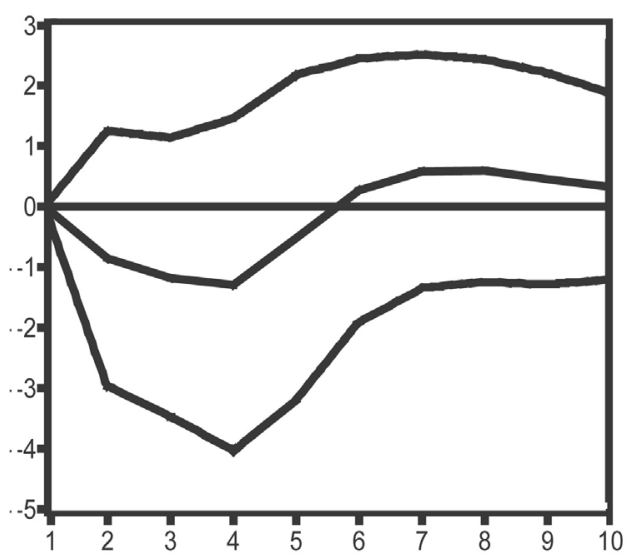

Response of CS to COMON

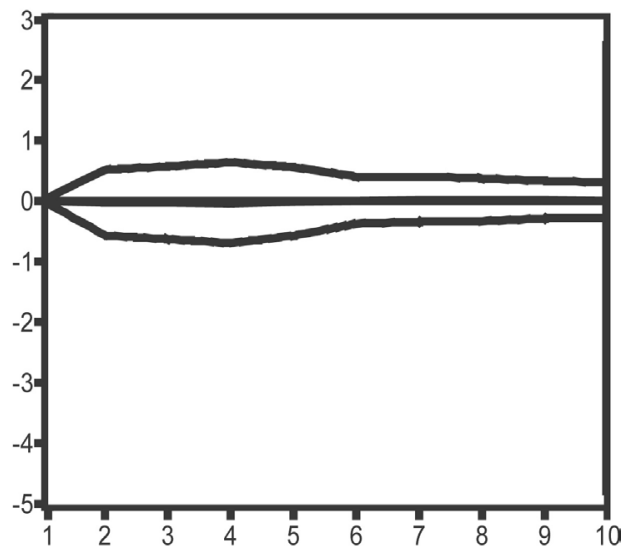

Response of CS to MP1

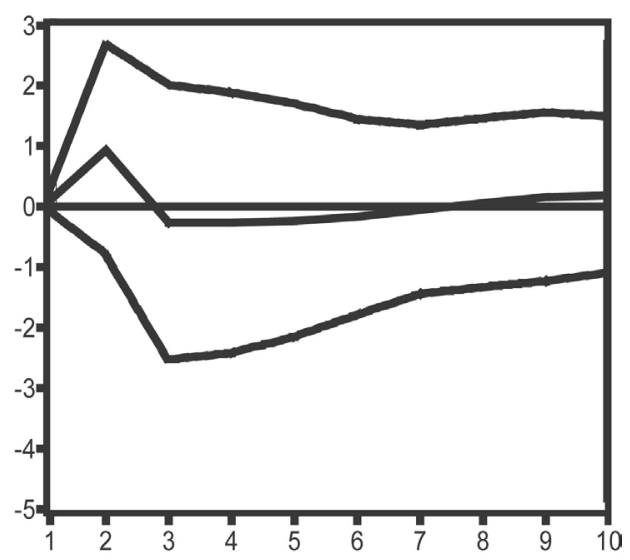


FIGURA 5 - RESPOSTAS DO PRODUTO DE CURTO PRAZO A IMPULSOS NA REGIÃO CENTRO-OESTE

Response of CCO to IDCO

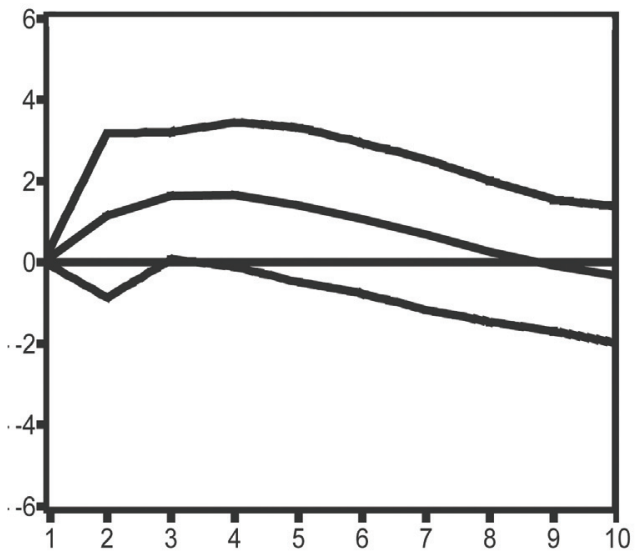

Response of CCO to OIL1

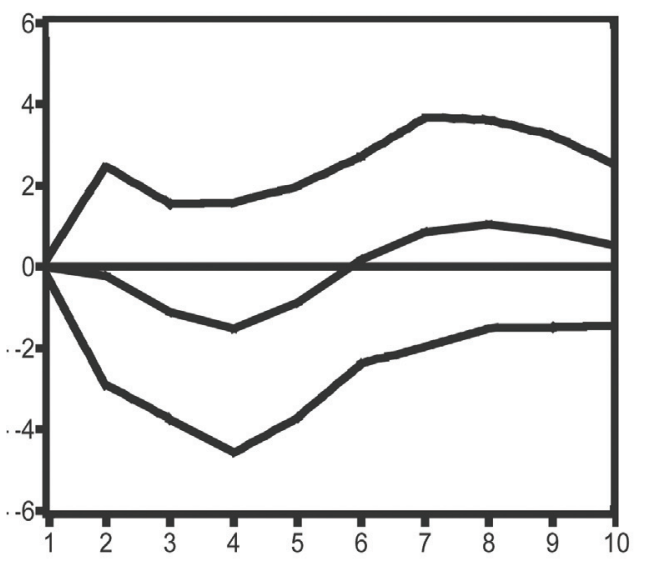

Response of CCO to COMON

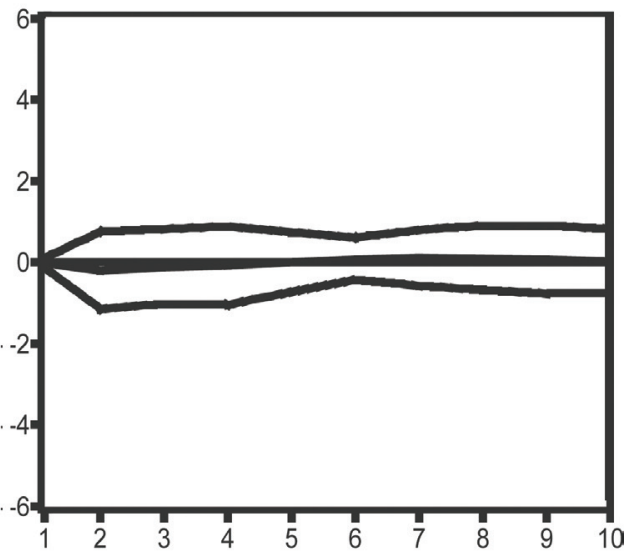

Response of CCO to MP1

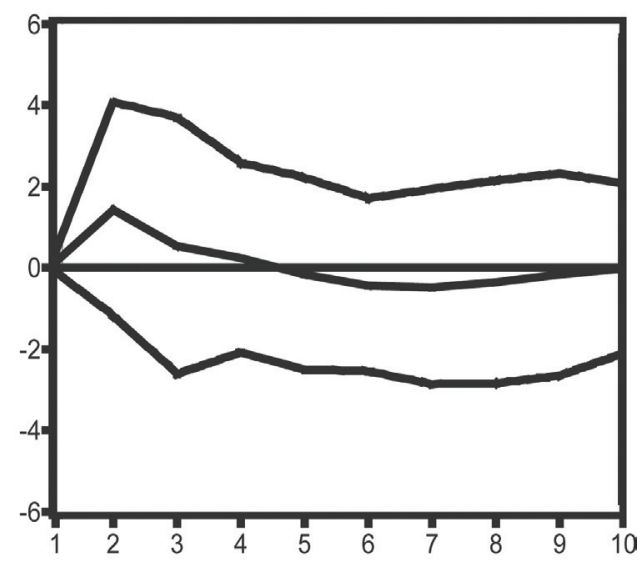


FIGURA 6 - RESPOSTAS DO COMPONENTE IDIOSSINCR ÁTICO A IMPULSOS NA REGIÃO SUDESTE

Response of IDSE to IDSE

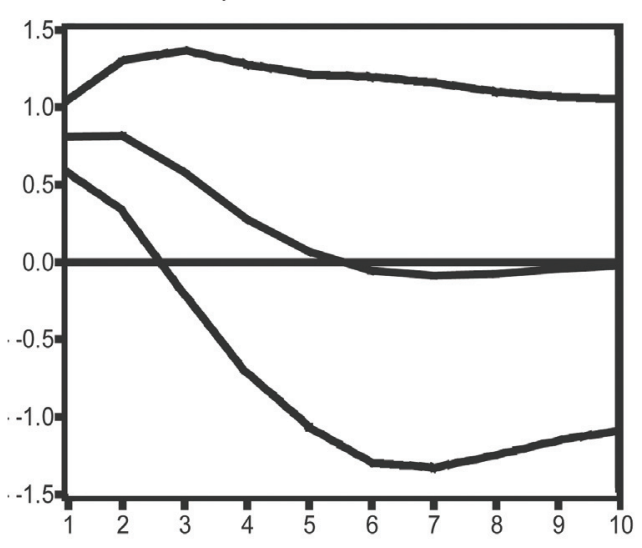

Response of IDSE to OIL1

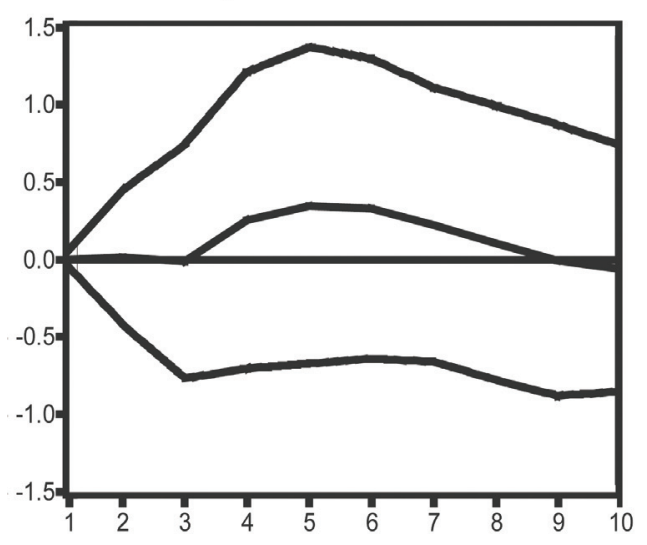

Response of IDSE to COMON

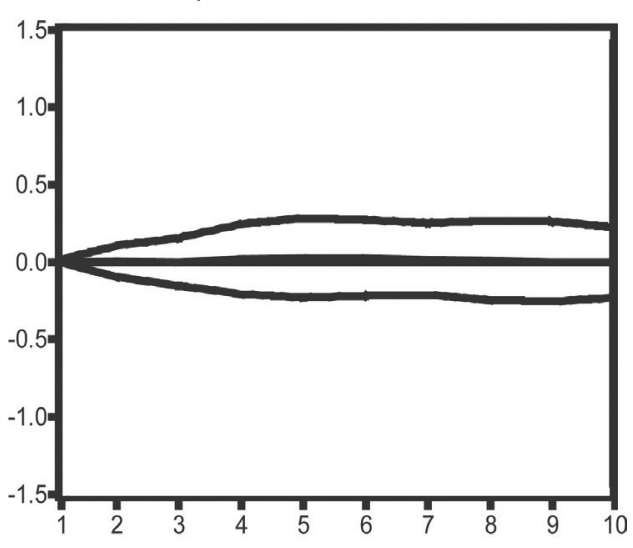

Response of IDSE to MP1

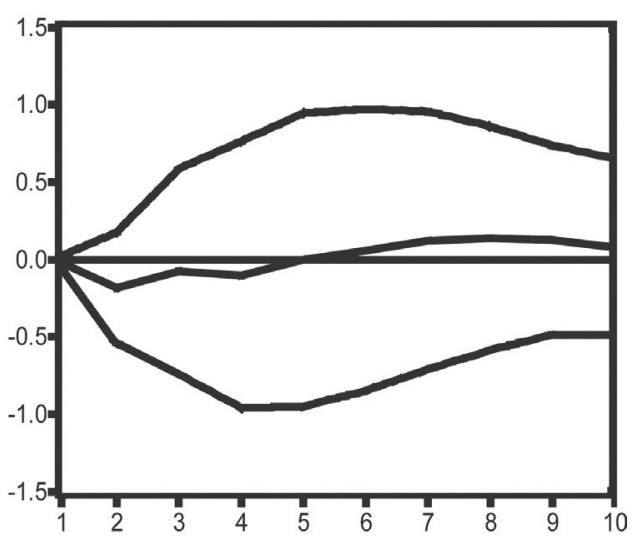


FIGURA 7 - RESPOSTAS DO COMPONENTE IDIOSSINCRÁTICO A IMPULSOS NA REGIÃO NORDESTE

Response of IDNE to IDNE

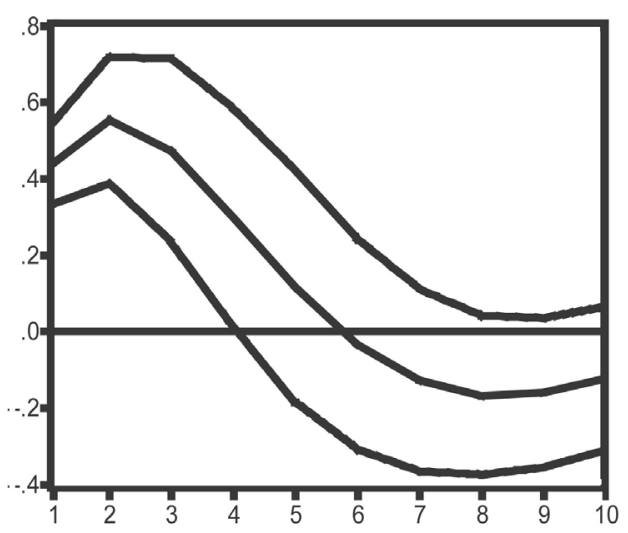

Response of IDNE to OIL1

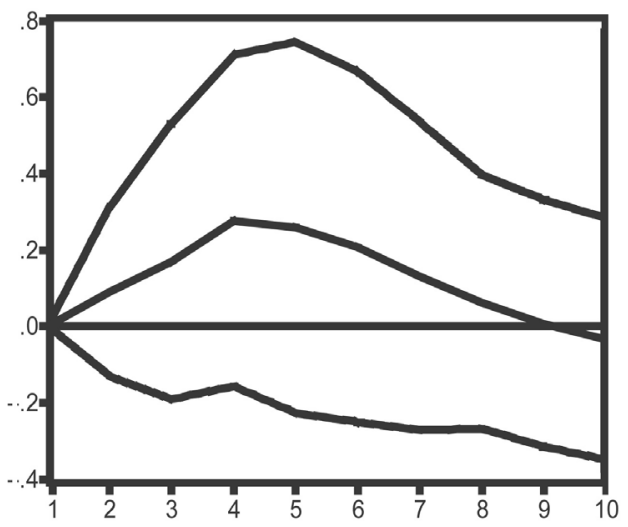

Response of IDNE to COMON

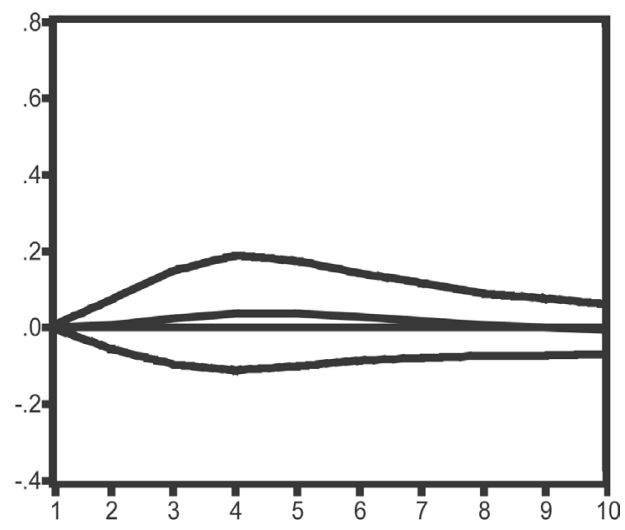

Response of IDNE to MP1

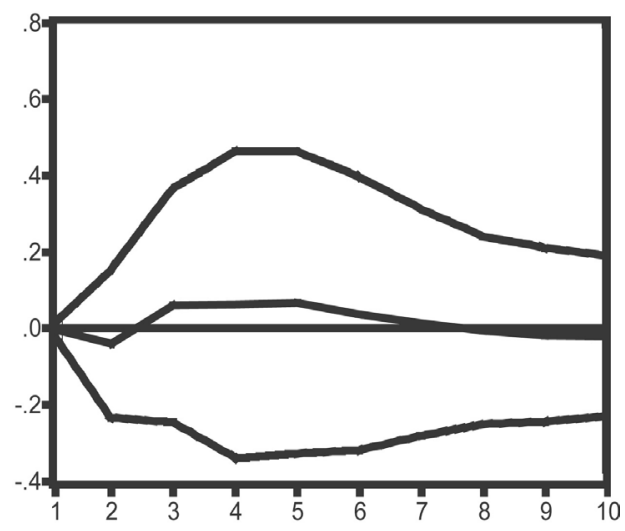


FIGURA 8 - RESPOSTAS DO COMPONENTE IDIOSSINCR ÁTICO A IMPULSOS NA REGIÃO NORTE

Response of IDN to IDN

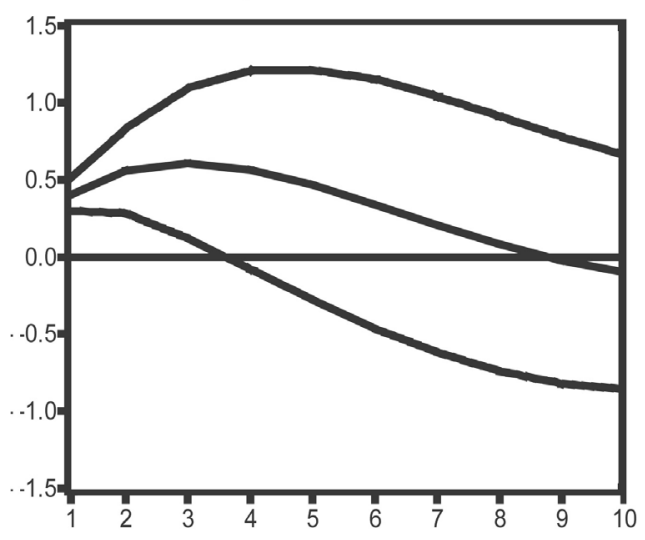

Response of IDN to OIL1

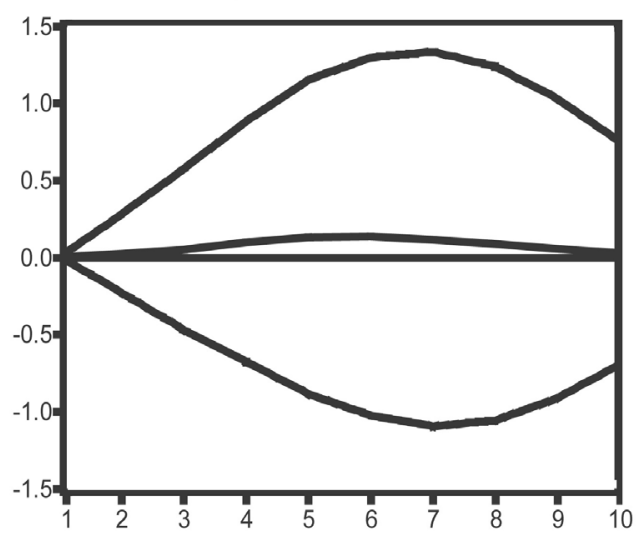

Response of IDN to COMON

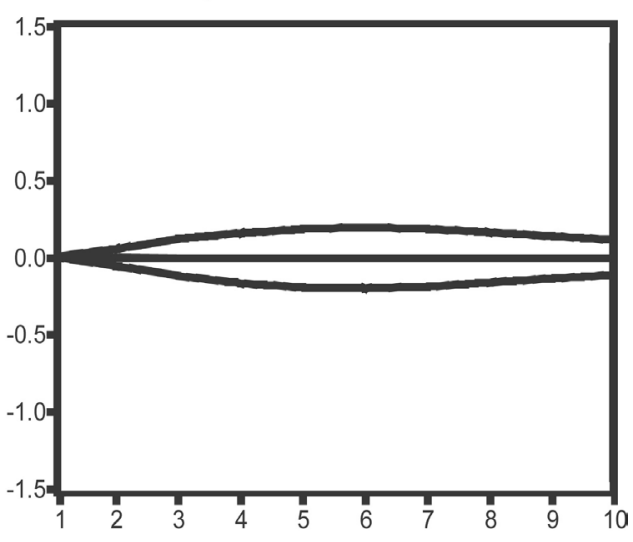

Response of IDN to MP1

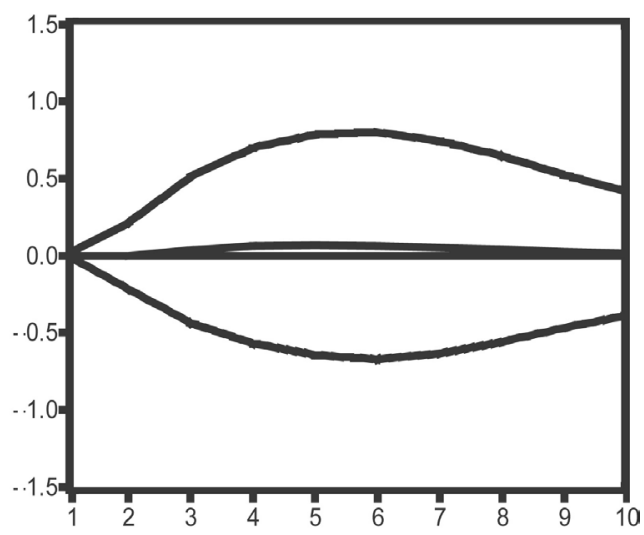


FIGURA 9 - RESPOSTAS DO COMPONENTE IDIOSSINCRÁTICO A IMPULSOS NA REGIÃO SUL

Response of IDS to IDS

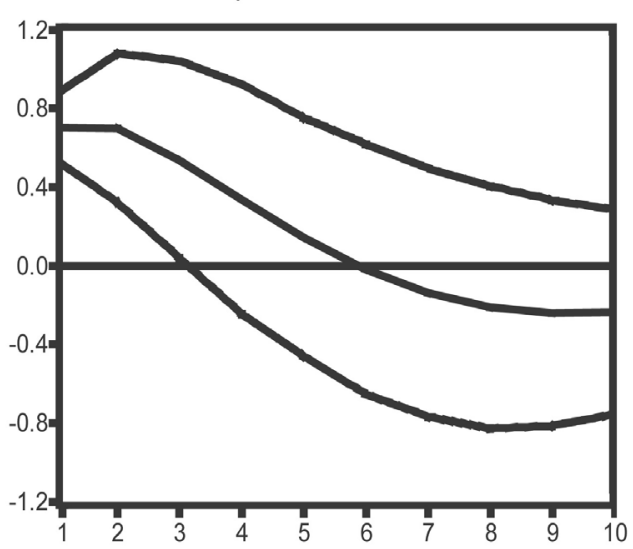

Response of IDS to OIL1

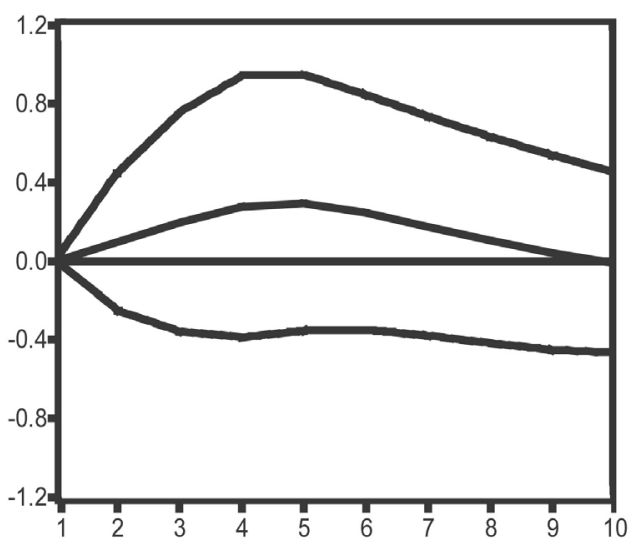

Response of IDS to COMON

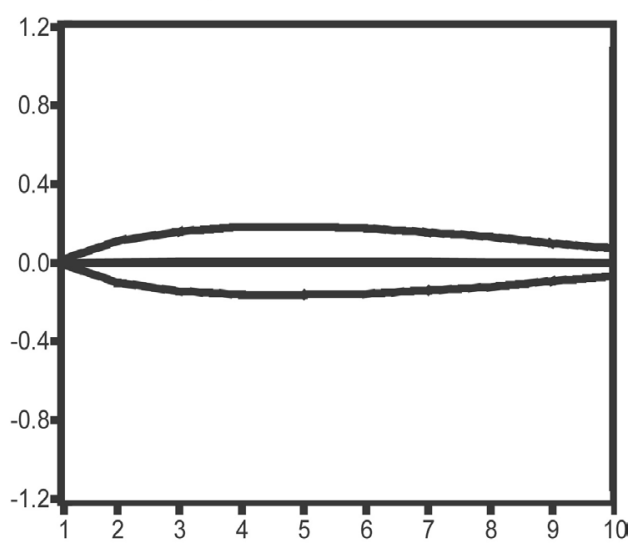

Response of IDS to MP1

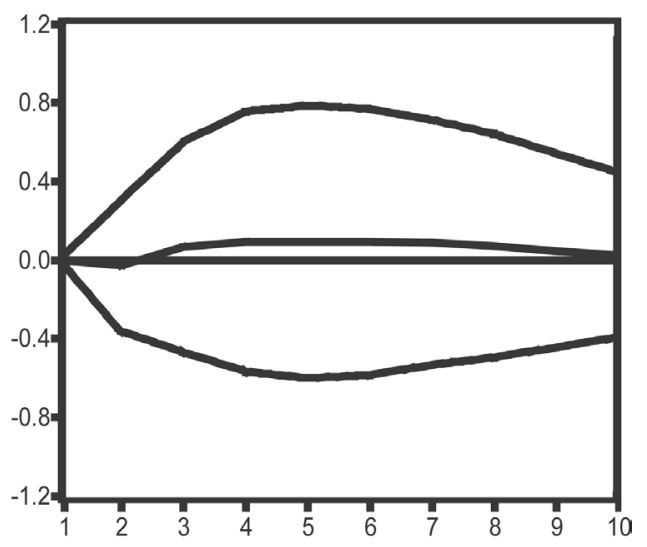


FIGURA 10 - RESPOSTAS DO COMPONENTE IDIOSSINCRÁTICO A IMPULSOS NA REGIÃO CENTRO-OESTE

Response of IDCO to IDCO

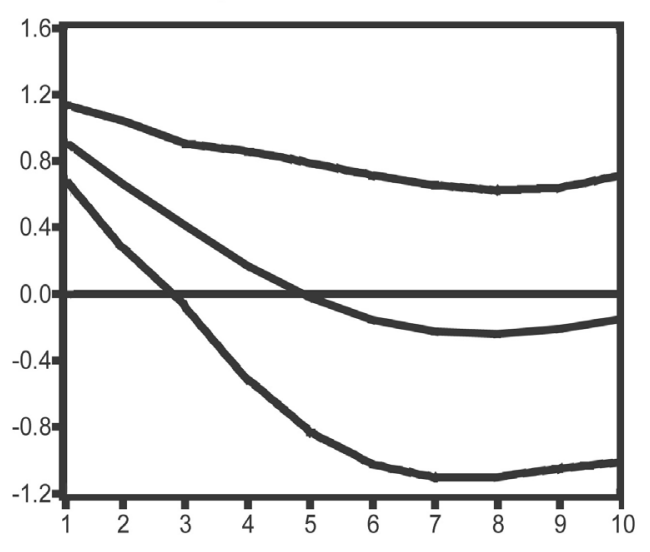

Response of IDCO to OIL1

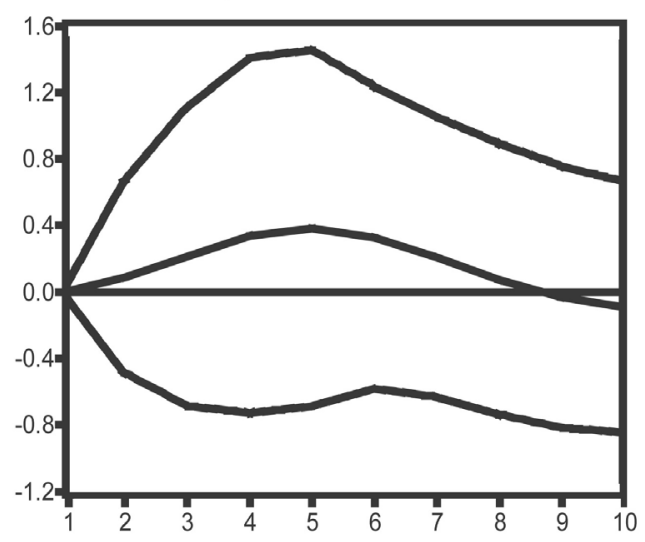

Response of IDCO to COMON

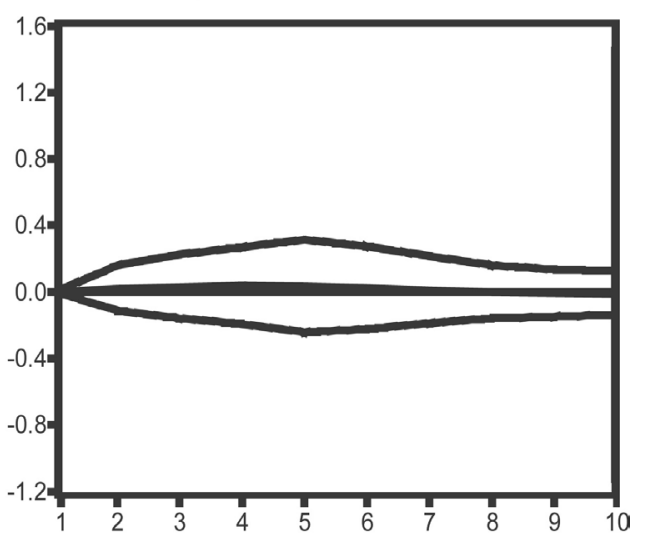

Response of IDCO to MP1

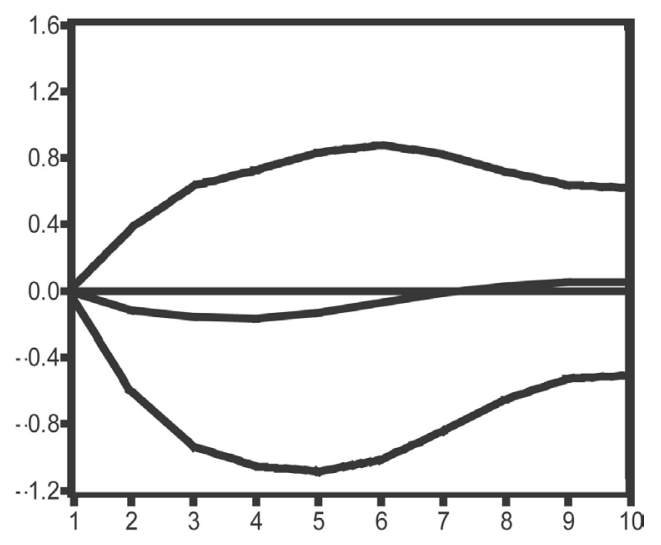

